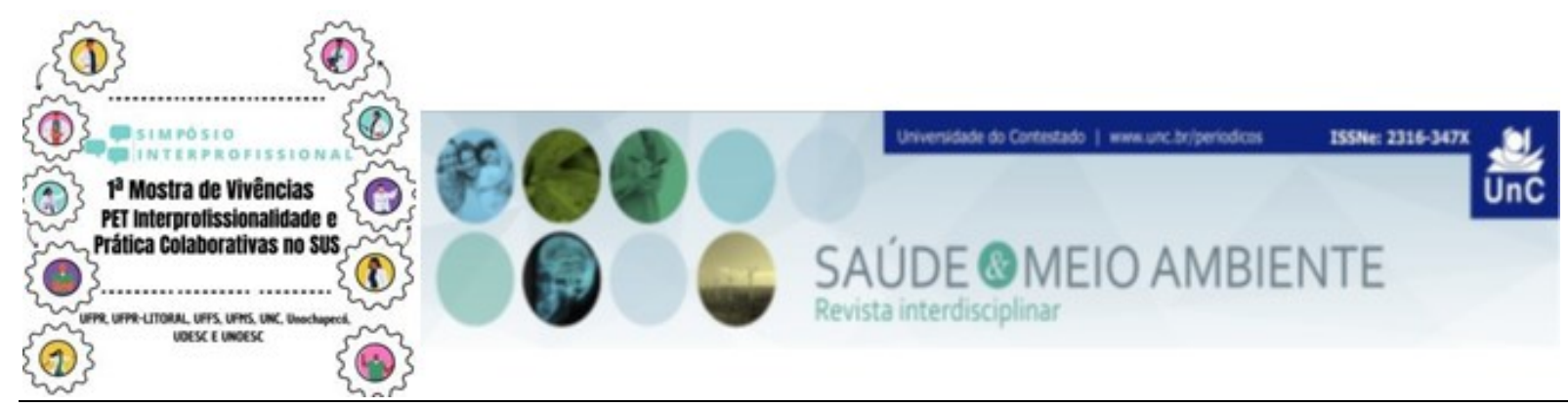

\title{
AÇÕES DE PROMOÇÃO DA SAÚDE DO PET-SAÚDE INTERPROFISSIONALIDADE NO GRUPO DAS PROFESSORAS DO ENSINO BÁSICO DE PARANAGUÁ-PR ${ }^{1}$
}

\author{
Projeto 93 Pet-Saúde Interprofissionalidade \\ Lígia Panhozi de Camargo Nogueira ${ }^{2}$ \\ Jéssica Fritz da Silva ${ }^{3}$ \\ Roberto Eduardo Bueno ${ }^{4}$ \\ Silmara Souza Lima ${ }^{5}$ \\ Alessandro Razzolini Lovera ${ }^{6}$ \\ Solange Barbosa Pinas ${ }^{7}$ \\ Ariadne Correia Barbosa ${ }^{8}$ \\ Evaldo Ribeiro Jr. ${ }^{9}$
}

\begin{abstract}
RESUMO
Introdução: A formação profissional tem sido direcionada para o trabalho em equipe, de modo que, profissionais com diferentes formações articulam seu saber específico com o dos outros. ${ }^{1}$ No ano de 2019 , o município de Paranaguá-PR juntamente com o Programa de Educação pelo Trabalho para a Saúde (PET-Saúde) da Universidade Federal do Paraná (UFPR) Litoral iniciou uma parceria, com várias ações, no Programa de Atenção à Saúde e Valorização do Professor (PASVP), com base na Política Nacional de Atenção Integral à Saúde da Mulher, incorporada nas primeiras décadas do século $X X$, voltadas na perspectiva da promoção e prevenção da saúde das profissionais docentes. ${ }^{3}$ Com a chegada da Pandemia por Covid-19, as professoras entraram em quarentena e as ações presenciais do PET-Saúde foram suspensas. Com o intuito de dar continuidade e incentivar ações de promoção de

${ }^{1}$ Fonte de financiamento: Programa de Educação pelo Trabalho para a Saúde - PET

Saúde/Interprofissionalidade 2019-2021 (Edital no 10 de 23 de julho de 2018, Ministério da

Saúde/Secretaria de Gestão do Trabalho e da Educação na Saúde).

2Bolsista no PET. Acadêmica do curso de Serviço Social. Universidade Federal do Paraná. Paraná.

Brasil. E-mail: ligiapanhozi@gmail.com

33olsista no PET. Acadêmica do curso de Saúde Coletiva. Universidade Federal do Paraná. Paraná.

Brasil. E-mail: jessicafritzsilva@gmail.com

4Tutor no PET. Docente do curso de Saúde Coletiva. Universidade Federal do Paraná. Paraná. Brasil.

E-mail: roberto.edu.bueno@gmail.com

${ }^{5}$ Preceptora no PET. Psicóloga no CMAE - Centro Municipal de Avaliação Especializado. Paraná.

Brasil. E-mail: psicopasp@gmail.com

${ }^{6}$ Bolsista no PET. Universidade Federal do Paraná. Paraná. Brasil. E-mail: praguirba@gmail.com

${ }^{7}$ Voluntária no PET. Universidade Federal do Paraná. Paraná. Brasil. E-mail: sobapi77@gmail.com

Voluntária no PET. Universidade Federal do Paraná. Paraná. Brasil. E-mail:

adne.correia@gmail.com

9Tutor no PET. Docente do curso de Educação Física da Universidade Federal do Paraná. Paraná.

Brasil. E-mail: evaldo.ribeirojr@ufpr.br
\end{abstract}


saúde, a equipe precisou se readaptar por meio de atividades remotas. Objetivo: Relatar as ações realizadas do grupo Pet-Saúde com o PASVP de Paranaguá-PR. Metodologia: Com enfoque de relato de experiência, demonstra-se a elaboração de atividades do PET-Saúde e PASVP desenvolvidas com as profissionais. No dia 18 de Março de 2020, foram formuladas ações, através de uma rede social, voltadas à pandemia, com informativos sobre Covid-19, à promoção de saúde física e mental, vídeos e informações breves sobre alimentação saudável, de maneira a incentivar um vínculo entre todos de forma remota. Resultados: Verificou-se que antes da pandemia tivemos uma grande participação das professoras em atividades como: caminhada no Parque Estadual do Palmito, subida ao morro do escalvado, atividades na ilha do mel, participação no I Seminário Intermunicipal Programa de Atenção à Saúde e ao Trabalho do Professor, ioga, e grande adesão (89 professoras) no estudo diagnóstico sobre a qualidade de vida, nível de atividade física e autoimagem destes profissionais. Nestas atividades pré-pandemia percebe-se que o elo de ligação está na interação social, principalmente nas atividades na natureza, o fato de ser atividades em grupo com interação social encorajou muito a participação maciça. A partir do isolamento social, o uso de aplicativo possibilitou a manutenção das ações do PETSaúde, com uma boa interação referente às informações de Covid-19 e pequena adesão às ações de promoção da saúde para os exercícios enviados. Conclusão: Observa-se que o PASVP foi percebido por sua importância de criar espaço para pensar a saúde das professoras. ${ }^{2}$ As ações integradas entre PET-Saúde e PASVP, nas atividades presenciais favoreceu uma maior adesão às atividades propostas, de forma a melhorar a socialização dos participantes e na atenção integral à saúde. Em relação às atividades remotas durante a pandemia, houve uma baixa adesão, refletindo uma possível sobrecarga dos profissionais em trabalho remoto, aumentando as queixas e atendimentos individuais com a psicóloga do projeto e servindo como análise situacional para elaboração de novas estratégias.

Palavras-chave: Educadores. Docentes. Promoção da Saúde. Qualidade de Vida. Saúde da Mulher.

\section{REFERÊNCIAS}

1- Matuda CG, Aguiar DML, Frazão P. Cooperação interprofissional e a Reforma Sanitária no Brasil: implicações para o modelo de atenção à saúde. Saúde Soc. São Paulo, 2013; 22(1):173-186.

2- Dalago IB. Programa de atenção à saúde e ao trabalho do professor municipal de Paranaguá: um estudo de caso. Programa de Pós-Graduação em Rede para o ensino das Ciências Ambientais. PROFCIAMB, UFPR: Matinhos; 2019.

3- Brasil, Ministério da Saúde. Secretaria de atenção à Saúde. Departamento de Ações Programáticas Estratégicas. Política Nacional de Atenção Integral à Saúde da Mulher: Princípios e Diretrizes. 1 ed., 2 reimpr. Brasília: Editora do Ministério da Saúde; 2011. 